\title{
IHC no Ensino Remoto Emergencial: Relato de Experiência
}

\author{
Erica Rodrigues de Oliveira \\ ${ }^{1}$ Centro Universitário Una - Belo Horizonte - MG - Brasil \\ profericaoliveira@gmail.com
}

\begin{abstract}
Resumo. Alinhado à temática do WEIHC 2020, "Reflexões sobre o uso das tecnologias digitais no ensino de IHC" este trabalho relata a experiência da disciplina de IHC em meio à pandemia provocada pelo Covid-19 numa instituição privada de ensino, no Brasil. Neste relato são apresentadas ferramentas e estratégias utilizadas com o intuito de contribuir com o ensino de IHC em tempos de ensino remoto emergencial. Os resultados apresentados demonstram que as ações foram avaliadas positivamente pelos estudantes, demonstrando que algumas dessas estratégias também podem contribuir para o aprendizado de IHC independente do ambiente: online, presencial ou híbrido.
\end{abstract}

\section{Introdução}

A disseminação do corona-vírus, ou Covid-19, por todo o mundo colocou a humanidade em uma situação sem precedentes [Barría 2020]. A população mundial foi intimada a ficar em casa para se cuidar e cuidar do outro. No Brasil, em março de 2020, as instituições de ensino fecharam por determinação dos governos estaduais para evitar a propagação do novo vírus. As instituições de ensino privadas fizeram vários esforços para garantir a continuidade das aulas no ambiente online, seja oferecendo treinamentos a professores como também investindo em tecnologia para que as aulas pudessem ter continuidade no ambiente online[Kuzuyabu and Oliveira 2020].

Neste sentido, foi necessário adaptar as aulas presenciais às aulas online, denominado ERE - ensino remoto emergencial. O ERE, segundo [Hodges et al. 2020] envolve o uso de soluções de ensino totalmente remotas para instrução ou educação que foi adotada de modo temporário para que as atividades escolares não sejam interrompidas. Neste ambiente não basta transformar a aula presencial em online, é necessário que haja inovação didática do professor, adequando os métodos de ensino à nova realidade imposta.

O objetivo deste trabalho é compartilhar a experiência vivenciada na disciplina de IHC, numa instituição de ensino superior privada, no Brasil, em meio à pandemia provocada pelo Covid-19. Por meio deste relato espera-se contribuir com outros docentes, especialmente de IHC, para tornar as aulas mais dinâmicas e promover o engajamento dos estudantes, contribuindo para o aprendizado significativo de IHC.

\section{Perfil da disciplina de IHC e dos estudantes}

No Centro Universitário Una, em Belo Horizonte, a disciplina de Interação HumanoComputador é ministrada no $1^{\circ}$ período do curso de Sistemas de Informação. Assim, logo no início do curso, os estudantes têm a oportunidade de compreender que os sistemas interativos são desenvolvidos para ajudar as pessoas. A disciplina tem carga horária de 80 horas/aula, sendo 40 aulas teóricas, em sala de aula, e 40 aulas no laboratório 
de informática, com aulas práticas. A ementa é composta por: Introdução à Interação Humano-Computador; Qualidades de uso; Princípios de Interface Humano Computador; Experiência do Usuário (UX); Usabilidade para interfaces desktop, web e mobile.

Este semestre, em função do Covid-19, os estudantes tiveram exatamente 16 horas/aula presencial, nos meses de fevereiro e março de 2020. Em março de 2020 foi decretado o fechamento das escolas e instituições de ensino na cidade de Belo Horizonte. Desde então, foi necessário adaptar as aulas e atividades da disciplina de IHC. Sobre o perfil da turma: havia 28 alunos matriculados nesta disciplina, sendo 3 meninas e 25 meninos. A maioria desses alunos estão na faixa etária de 18 a 25 anos e cursam sua primeira graduação. A seguir são apresentadas as estratégias utilizadas para realização das aulas.

\section{Ferramentas e estratégias utilizadas para realização das aulas}

No início das aulas online, a instituição de ensino disponibilizou duas possibilidades de ferramentas para as aulas síncronas, Google Meet e Zoom. A ferramenta escolhida pela educadora foi o Google Meet, dada sua boa usabilidade e facilidade para gravação das aulas, integrada ao próprio Google Drive institucional. Todas as aulas eram gravadas e disponibilizadas integralmente, sem edição, para os alunos.

O recurso de gravação das aulas foi muito elogiado pelos alunos, pois vários deles tinham limitações com a conexão de internet, e.g. instabilidade na conexão. Com a gravação, os alunos podiam assistir as aulas posteriormente e também rever algum conteúdo para sanar dúvidas.

O ambiente virtual de aprendizagem (AVA) usado para disponibilizar materiais e entrega de atividades foi o Google Classroom. Nele, os estudantes tinham acesso aos conteúdos abordados nas aulas, sugestões de leitura, atividades, etc. A centralização das informações nesta plataforma foi importante para a organização da disciplina, bem como para que os estudantes pudessem localizar facilmente os conteúdos e atividades a realizar.

No ambiente online também foi necessário criar diferentes canais de comunicação, assegurando que informações importantes chegassem no tempo devido, (e.g. atividades avaliativas). Assim, frequentemente o professor enviava $e$-mails avisando sobre atividades avaliativas e demais entregas importantes. Além disso, também eram enviadas mensagens pelo whatsapp, via representante de turma, para que a mensagem pudesse ser encaminhada ao grupo da turma, como segundo meio de comunicação. Na seção seguinte, são apresentadas estratégias de afetividade utilizadas.

\section{Criando vínculo e promovendo o engajamento com os estudantes}

[Coates 2009] define engajamento como o "envolvimento dos estudantes com atividades e condições que possam gerar aprendizagem de alta qualidade". Neste sentido, na relação docente-discente faz-se necessária a criação de um ambiente pautado na solidariedade e empatia, especialmente em meio a pandemia provocada pelo Covid-19. Assim, quanto maior a interação do docente no sentido de oferecer suporte aos discentes, maiores são as chances de promover um bom engajamento dos estudantes.

Promover o engajamento do aluno em sala de aula presencial é um desafio, pois requer, segundo [Zepke and Leach 2010], motivação do aluno, relações entre professores e alunos, apoio institucional e desenvolvimento da cidadania ativa. No ensino remoto 
emergencial (ERE) esse desafio aumenta consideravelmente, pois em meio a um cenário de crise, ele precisa ter autoestima e confiança em si próprio, exercendo o seu protagonismo.

A fim de buscar uma aproximação dos estudantes, na primeira semana de aula os alunos foram convidados a escrever um texto sobre si mesmo. O texto inicia com "Eu gostaria que minha professora soubesse...”. Com esse texto, a educadora teve a oportunidade de conhecer um pouco seus alunos. Assim, ocorreu uma aproximação do educador com a realidade de cada aluno. Para as aulas online, esse conhecimento prévio sobre os estudantes foi um diferencial para auxiliar no engajamento e motivação dos alunos.

Problemas de infraestrutura (e.g. dificuldade de acesso à internet) impediram alguns alunos de acessar o link para participar das aulas síncronas. Para controle pessoal, a docente criou um formulário online para identificar quais alunos estavam presentes na aula síncrona. Semanalmente, a educadora comparava essa listagem com os alunos matriculados, para verificar quais alunos estavam ausentes nas aulas síncronas. Assim, semanalmente a professora enviava $e$-mails individuais aos alunos ausentes para identificar o motivo da ausência. Isso criou uma proximidade com o estudante e ele sabia que sua ausência era percebida pela educadora. Esta ação foi feita nas primeiras semanas do isolamento social e, em meados do semestre, foi possível perceber sua eficácia. Os estudantes, quando tinham alguma dificuldade e não conseguiam participar da aula síncrona, enviavam email à professora para justificar o motivo da ausência.

Para acolher os estudantes em suas necessidades individuais foi criado um canal de comunicação denominado Projeto Mentoria. Essa ação teve como objetivo ser um espaço para o aluno falar sobre sua vida profissional, acadêmica e pessoal. Tratava-se de um encontro online, síncrono, fora do horário de aula para atender o aluno individualmente e fornecer apoio e orientações que pudessem contribuir na formação do discente. Durante o isolamento social vários estudantes buscaram essa ajuda, porque estavam com dificuldades de adaptação ao novo modelo imposto, de ensino online, assim como melhoria do currículo para buscar novas oportunidades de trabalho, inseguranças geradas pelo Covid-19, dentre outras. A seguir, são apresentadas as atividades realizadas no ERE no contexto de IHC.

\section{Atividades Realizadas}

Para incentivar os estudantes a participarem ativamente das aulas de IHC, a professora utilizou diferentes recursos, que são apresentados a seguir.

Acessibilidade: nesta aula o objetivo era trabalhar os conceitos envolvidos nesta qualidade de uso e promover uma reflexão sobre a importância de produzir interfaces acessíveis. Individualmente os alunos foram conduzidos pela professora e fizeram a atividade Bengala Legal, proposta por [Falcão 2018].

Comunicabilidade: nesta aula o objetivo era que os alunos compreendessem a importância da comunicabilidade em uma interface, avaliando também o que é uma boa ou má comunicabilidade. Para isso, foi feita uma adaptação do jogo Imagem e Ação. A turma se dividiu em pequenos grupos no Google Meet. Cada grupo deveria escolher 4 ícones e fazer o desenho desse ícone na ferramenta Paint. Os demais grupos deveriam adivinhar qual era o ícone e sua funcionalidade. Os estudantes se divertiram com essa 
atividade e perceberam o quanto é desafiador se comunicar de modo eficaz e eficiente com os usuários. Além disso, discutiram sobre questões de baixa e alta comunicabilidade das imagens criadas, bem como dos desafios de representar ícones e sua funcionalidade.

Avaliação da compreensão do conteúdo: com o intuito de verificar o nível de compreensão dos alunos sobre os conteúdos abordados foram utilizadas ferramentas como formulário do Google, Socrative e Kahoot, sugerida por [Silveira 2019]. O Kahoot foi muito elogiado pelos alunos, por utilizar a gamificação, diferente das demais. Os estudantes sentiam-se motivados a estudar o conteúdo, pois almejavam obter uma boa pontuação no quiz. Para valorizar e reconhecer os alunos que obtinham as melhores pontuações, a professora inseriu o ranking no AVA da disciplina. Com isso, outros estudantes também desejavam estar no ranking e para isso, estudavam o conteúdo com afinco. O Kahoot foi utilizado em 2 momentos do semestre: aulas anteriores às avaliações e aula sobre avaliação heurística, para consolidação do aprendizado. Formulários do Google e Socrative foram utilizados como ferramentas para as avaliações formais.

Talk com convidados: foram realizadas 2 talks com convidados. A primeira contou com a participação de 2 alunos, sendo um ex aluno e um veterano matriculado no último semestre do curso. Ambos foram destaques no curso de Sistemas de Informação da Una e atuam em renomadas empresas na área de tecnologia. O objetivo desta talk era inspirar os alunos por meio dos exemplos de seus pares, contribuindo para a melhora da autoestima e autoconfiança, mostrando que eles também podem obter boas oportunidades de trabalho. Além disso, por se tratar de uma turma de alunos calouros, para muitos deles este foi o primeiro contato que tiveram com profissionais atuantes na área de TI. A segunda talk foi com uma designer que atua numa grande empresa. Nesta talk a proposta era trazer um pouco do mercado de trabalho para dentro da sala de aula. Assim, os estudantes tiveram a oportunidade de compreender como o conteúdo visto nas aulas é utilizado na prática. Após a realização das talks, os estudantes foram convidados a registrar sua opinião sobre as mesmas. De modo geral os estudantes gostaram das palestras, pois foi possível aumentar o networking, ampliar o conhecimento sobre as possibilidades de atuação no mercado de trabalho e sair da rotina das aulas com convidados externos.

Trabalho Prático - TP: o alinhamento construtivo parte do princípio de que o estudante constrói seu aprendizado por meio de atividades de aprendizagem relevantes. Esse significado é desenvolvido pelo próprio estudante à medida que o professor cria um ambiente que maximize a probabilidade dos estudantes se engajarem nas atividades desenvolvidas para alcançar os objetivos estabelecidos previamente [Biggs 2003].

Neste contexto, foi proposto aos estudantes o desenvolvimento de um trabalho prático que compreendeu a criação de uma solução tecnológica voltada para pessoas maiores de 60 anos, os idosos. A solução deveria auxiliar os idosos na utilização de tecnologia, podendo ser um aplicativo, jogo ou outra ferramenta que possa auxiliar os idosos em tempos de isolamento social, provocado pelo (Covid - 19), uma vez que essa grande parcela da população foi muito afetada pela pandemia, por ser um grupo vulnerável.

Neste trabalho era esperado que os estudantes pudessem trabalhar uma situação real do processo de design de interação, além de contribuir com o desenvolvimento de habilidades socioemocionais, como trabalho em equipe, gestão do tempo, etc. O produto final deste projeto buscou promover a inclusão e acessibilidade digital, e o bem-estar 
social dos idosos, além de conscientizar os estudantes sobre a importância de oferecer uma contribuição social para a comunidade no seu entorno. Assim, essa proposta era também uma oportunidade para que os estudantes pudessem se conectar a familiares que são de outra geração, como os pais, avós e outros, uma vez que não poderiam sair de casa para fazer os testes necessários nas ferramentas criadas por eles.

O trabalho foi realizado em equipes compostas por 4 a 5 membros, onde cada um exercia um papel (e.g. analista, designer ou gerente de projeto). Foi utilizado o Design Thinking [Brown 2018], que é uma metodologia prática, centrada no usuário para a solução de problemas. Essa metodologia foi escolhida por ser amplamente utilizada no mercado de trabalho e por ser uma ferramenta que auxilia na resolução de problemas.

\section{Análise dos estudantes sobre as aulas de IHC}

Por ter sido um semestre atípico em função da pandemia e da necessidade de adaptação rápida ao novo cenário, ao longo do semestre a educadora utilizou ferramentas como formulários online para perguntar a opinião dos estudantes sobre as aulas, estratégias adotadas e o que poderia ser melhorado. A seguir são apresentados os resultados da análise dos comentários feitos pelos estudantes considerando: (i) opinião sobre as aulas de IHC e (ii) ferramentas ou ações preferidas.

Opinião sobre as aulas de IHC: de modo geral os estudantes ficaram satisfeitos com a dinâmica das aulas. Segundo eles houve um esforço por parte da educadora em se adaptar ao novo modelo de aulas online, utilizando diferentes estratégias e tornando a aula dinâmica e engajadora. Além disso, conforme o E1, "a professora foi além do conteúdo, se preocupando com o lado humano dos estudantes, com dicas de saúde mental, gerando engajamento e demonstrando empatia conosco". Isso demonstra a importância da afetividade, do cuidado com o estudante enquanto ser humano para engajar e promover um espaço de aprendizado, especialmente em meio à pandemia. Além disso, conforme o E6 “o TP foi uma oportunidade de estar mais próximo da família, dos idosos...”. Aqui fica claro que o objetivo de aproximar o estudante dos idosos da família também foi alcançado. Já E10 ressalta: "Mais do que nunca foi necessário que os estudantes trabalhem de forma cooperativa e coletiva para absorver e construir o conhecimento de forma conjunta.". Esse comentário reforça a necessidade do senso coletivo para o processo de aprendizado para os estudantes. E10 conclui: “...os professores terão que repensar a forma de realizar avaliações também, porque esse modelo não foi feito para uma realidade virtual onde os estudantes podem interagir entre si."

Ações realizadas: sobre o TP, os estudantes tiveram a oportunidade de vivenciar na prática o processo de design de interação, passando por todas as etapas, desde a concepção aos testes. O TP proporcionou aos estudantes maior interação entre os membros do grupo, desenvolvimento de habilidades socioemocionais e prática do conteúdo teórico. Segundo o estudante 2, E2: "No TP coloquei em prática o conhecimento de IHC, desde entender como a interface deve ser montada pensando diretamente no público alvo, a como conseguir dados desse público, entender as dificuldades, imaginar possíveis problemas, adaptar o programa (no nosso caso, o jogo), etc”. E9 relatou sobre a realização do trabalho em etapas: "O TP foi muito importante porque foi feito em etapas que consolidavam os conceitos aprendidos, então enquanto a turma aprendia a teoria já podia (ir) aplicando a prática. Para mim, foi a melhor forma de aprendizado." 
Os estudantes também destacaram a necessidade de disciplina por parte dos alunos para estudar e participar ativamente das aulas online; maior aproximação com os colegas por meio do TP; e os jogos (Kahoot) que faziam os estudantes aprenderem de modo lúdico. Além disso, a comunicação frequente e em diversas plataformas foi destacada pelos estudantes, assim como o envio de conteúdos adicionais à disciplina, contribuindo para que os estudantes fossem além do que foi abordado nas aulas. Outra ação ressaltada foram as talks que contribuíram para uma conexão com o mercado de trabalho, bem como a aula online no horário respectivo e a gravação da mesma, para consulta posterior.

\section{Considerações Finais}

Neste trabalho, descrevemos um conjunto de atividades realizadas na disciplina de IHC, em meio à pandemia do Covid-19 no ensino remoto emergencial, no Brasil. O intuito deste relato é compartilhar as experiências realizadas nesta nova modalidade de ensino e que proporcionaram o engajamento por parte dos estudantes da referida instituição. Assim, acredita-se que este compartilhamento pode ser útil a professores, especialmente da área de IHC.

Como trabalho futuro pretende-se aplicar essas atividades em outras turmas, em outras modalidades de ensino (e.g. presencial, online ou híbrido), a fim de investigar a efetividade dessas ações. Também pretende-seinvestigar as vantagens e desafios de trabalhar IHC no primeiro período do curso.

\section{Referências}

Barría, C. (2020). Coronavírus: avanço rápido de pandemia põe mundo 'muito perto de uma recessão global' - bbc news brasil. https : / / www. bbc.com/portuguese / internacional-51858298. (Accessed on 09/22/2020).

Biggs, J. (2003). Aligning teaching for constructing learning. Higher Education Academy, 1(4).

Brown, T. (2018). Design Thinking: uma metodologia poderosa para decretar o fim das velhas ideias. Alta Books Editora.

Coates, H. (2009). Engaging students for success-2008 australasian survey of student engagement. Victoria, Australia: Australian Council for Educational Research.

Falcão, T. P. (2018). Miniatividades sobre conceitos básicos de ihc: Dinamizando as aulas expositivas. In Anais Estendidos do XVII Simpósio Brasileiro sobre Fatores Humanos em Sistemas Computacionais. SBC.

Hodges, C., Moore, S., Lockee, B., Trust, T., and Bond, A. (2020). The difference between emergency remote teaching and online learning. Educause Review, 27.

Kuzuyabu, M. and Oliveira, D. (2020). Como estão as atividades acadêmicas em tempos de covid-19. https://revistaensinosuperior.com.br/ atividades-academicas-covid/. (Accessed on 09/22/2020).

Silveira, M. (2019). Praticando a teoria no ensino de ihc: dinamizando aulas teóricas com o uso de atividades práticas. In Anais Estendidos do XVIII Simpósio Brasileiro sobre Fatores Humanos em Sistemas Computacionais, pages 112-115. SBC.

Zepke, N. and Leach, L. (2010). Improving student engagement: Ten proposals for action. Active learning in higher education, 11(3):167-177. 